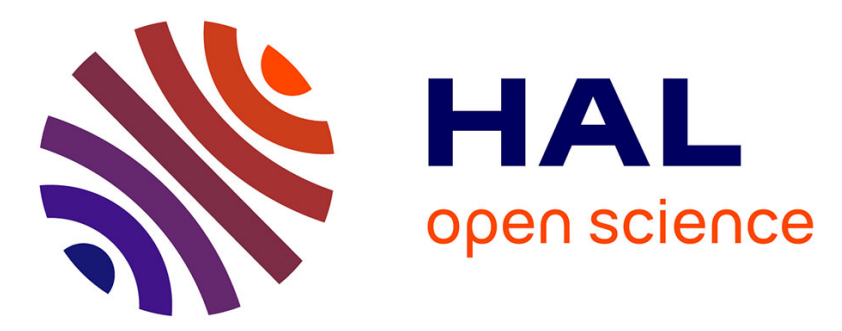

\title{
An easy method of preparing ozone gas sensors based on $\mathrm{ZnO}$ nanorods
}

\author{
Ariadne C. Catto, Luis F. Da Silva, Caue Ribeiro, Sandrine Bernardini, \\ Khalifa Aguir, Elson Longo, Valmor. R. Mastelaro
}

\section{- To cite this version:}

Ariadne C. Catto, Luis F. Da Silva, Caue Ribeiro, Sandrine Bernardini, Khalifa Aguir, et al.. An easy method of preparing ozone gas sensors based on ZnO nanorods. RSC Advances, 2015, 5 (25), pp.19528-19533. 10.1039/c5ra00581g . hal-01631653

\section{HAL Id: hal-01631653 \\ https://hal.science/hal-01631653}

Submitted on 29 Jan 2018

HAL is a multi-disciplinary open access archive for the deposit and dissemination of scientific research documents, whether they are published or not. The documents may come from teaching and research institutions in France or abroad, or from public or private research centers.
L'archive ouverte pluridisciplinaire HAL, est destinée au dépôt et à la diffusion de documents scientifiques de niveau recherche, publiés ou non, émanant des établissements d'enseignement et de recherche français ou étrangers, des laboratoires publics ou privés. 


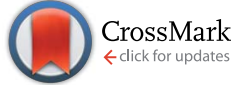

Cite this: RSC Adv., 2015, 5, 19528

Received 11th January 2015 Accepted 9th February 2015

DOI: $10.1039 / \mathrm{c} 5 \mathrm{ra00581g}$

www.rsc.org/advances

\section{An easy method of preparing ozone gas sensors based on ZnO nanorods $\uparrow$}

\author{
Ariadne C. Catto, ${ }^{a}$ Luís F. da Silva, ${ }^{\text {b }}$ Caue Ribeiro, ${ }^{c}$ Sandrine Bernardini, ${ }^{d}$ \\ Khalifa Aguir, ${ }^{d}$ Elson Longo ${ }^{b}$ and Valmor. R. Mastelaro ${ }^{a}$
}

\begin{abstract}
One-dimensional (1D) ZnO nanorod-like structures were successfully grown via a hydrothermal method to be used as an ozone gas sensor. X-ray diffraction measurements (XRD) and field-emission scanning electron microscopy (FE-SEM) analysis revealed a preferential growth of the nanorod-like structures along the [002] direction. Electrical resistance measurements indicated a good sensitivity to different ozone concentrations $(0.06-1.19 \mathrm{ppm})$ as well as long-term stability over a 6 month period at $250{ }^{\circ} \mathrm{C}$. In addition, it was observed that the nanorods had a good sensitivity to ozone at room temperature when the sensor was exposed to UV illumination. This study provides an easy and efficient way to obtain 1-D $\mathrm{ZnO}$ nanorods exhibiting remarkable properties for applications as ozone gas sensing materials.
\end{abstract}

\section{Introduction}

Chemical gas sensors have been applied in many areas, such as agriculture, medical diagnosis and detection of environmental pollutants and toxins. ${ }^{\mathbf{1 - 4}}$ For gas sensor devices of the highest sensitivity, it is desirable that the sensing material exhibit a large surface-area-to-volume ratio, which favors the adsorption of the gases on its surface. ${ }^{5}$ For this reason, sensor devices have been developed based on one-dimensional (1-D) nanostructures, such as nanowires, nanotubes, nanorods and nanobelts. ${ }^{6-10}$ Due to their unique characteristics, 1-D ZnO nanostructured material has been widely studied for numerous applications. $^{\mathbf{8 , 1 1}}$ Recently, ZnO nanorods arrays have also received considerable attention in photo-activated applications, in particular, photo-induced superhydrophilicity and photocatalysis. ${ }^{\mathbf{1 1}}$

A number of chemical and/or physical methods have been employed in the production of gas sensor based on 1-D $\mathrm{ZnO}$ nanostructure; these include metal-organic chemical vapor deposition (MOCVD), ${ }^{\mathbf{1 4}}$ pulsed laser deposition (PLD), ${ }^{\mathbf{1 5}}$

${ }^{a}$ Instituto de Física de São Carlos, Unversidade de São Paulo, Avenida Trabalhador São-carlense, 400, 13566-590 São Carlos, SP, Brazil

${ }^{b}$ LIEC, Instituto de Química, Universidade Estadual Paulista, P.O. Box 355, 14800-900 Araraquara, SP, Brazil.E-mail: lfsilva83@gmail.com

${ }^{c}$ EMBRAPA Instrumentação, Rua XV de novembro, 1452, 13560-970 São Carlos, SP, Brazil

${ }^{d}$ Aix Marseille Université, CNRS IM2NP (UMR7334), FS St Jérôme S152, Marseille, 13397, France

$\uparrow$ Electronic supplementary information (ESI) available: The detailed synthesis procedure of hierarchical ZnO nanorod-like structures, Zn K-edge XANES spectrum of ZnO nanorods, EDX spectrum, and electrical response of $\mathrm{ZnO}$ nanorods under UV irradiation. See DOI: 10.1039/c5ra00581g chemical vapor deposition (CVD), ${ }^{12}$ molecular beam epitaxy (MBE) ${ }^{13}$ sputtering, ${ }^{16}$ and electrodeposition. ${ }^{17}$

However, usually these methods require relatively high energy consumption during the synthesis in terms of temperature, pressure and/or vacuum. In contrast, wet chemical methods such as hydrothermal/solvothermal have allowed obtain 1-D ZnO nanostructures using a simple, effective, and reproducible procedure. ${ }^{18}$ Although several research groups have studied gas sensors based on 1-D ZnO nanorods via hydrothermal treatment, ${ }^{\mathbf{1 9}, 20}$ few studies have been carried out on the sensing properties of 1-D ZnO nanorods towards ozone gas.

It is important to emphasize that human exposure to ozone gas at the level higher than certain threshold value $(0.12 \mathrm{ppm})$ are likely to result in serious health problems (e.g. headache, burning eyes, respiratory irritation and lung damage). ${ }^{7}$ In a recent study, Chien and co-workers ${ }^{12}$ reported the ozone sensing properties of 1-D ZnO nanorods deposited via CVD technique. ${ }^{\mathbf{1 2}}$ Their obtained results indicated that 1-D ZnO nanorods exhibited good sensitivity to different ozone concentrations ( 1 to $2.5 \mathrm{ppm}$ ), however, this gas detection range is well above of the minimum recommended level. ${ }^{12}$

We report here on a simple, versatile, and low-cost strategy for obtaining ozone gas sensors based on hierarchical 1-D ZnO nanorod-like structures. To our best knowledge, this is the first study where the hydrothermal treatment method was used to grow 1-D ZnO nanorods directly onto interdigitated electrodes, facilitating the integration of sensing material into the ozone gas sensor device. Electrical resistance measurements at $250{ }^{\circ} \mathrm{C}$ showed that the 1-D ZnO nanorods were sensitive even at a lower ozone concentration (0.06 ppm), exhibiting fast response time and long-term stability over a period of 190 days. Additionally, these 1-D ZnO nanorods had relative good ozone 
gas sensing performance at room temperature when the sample was exposed to UV-light irradiation.

\section{Experimental section}

\subsection{Synthesis procedure}

ZnO hexagonal nanorod-like structures were grown via the hydrothermal method directly onto a $\mathrm{SiO}_{2} / \mathrm{Si}$ substrate with interdigitated Pt electrodes covered with a $\mathrm{ZnO}$ seed layer. Initially, a nanocrystalline $\mathrm{ZnO}$ thin film, which acted as a seed layer, was deposited onto a pre-cleaned $\mathrm{SiO}_{2} / \mathrm{Si}$ substrate with interdigitated Pt electrodes via the spin-coating technique.

$\mathrm{ZnO}$ hexagonal nanorod-like structures were grown in aqueous solutions using, zinc nitrate $\left[\mathrm{Zn}\left(\mathrm{NO}_{3}\right)_{2} \cdot 6 \mathrm{H}_{2} \mathrm{O}\right.$, Aldrich, $\left.>99 \%\right]$ and hexamethylenetetramine $\left(\mathrm{C}_{6} \mathrm{H}_{12} \mathrm{~N}_{4}\right.$, HMTA, Aldrich, $\left.>99 \%\right)$ in a molar concentration of $0.055 \mathrm{~mol} \mathrm{~L}^{-1}$ and $0.1 \mathrm{~mol} \mathrm{~L}^{-1}$, respectively. The reagents were separately dissolved in deionized water at room temperature and the HMTA solution then slowly added to the zinc solution under continuous stirring. The $\mathrm{SiO}_{2} / \mathrm{Si}$ substrate with interdigitated Pt electrodes covered with a ZnO seed layer was placed in a glass bottle containing the resulting transparent solution. The substrate surface containing the $\mathrm{ZnO}$ seed layer was face down in the bottom of the glass bottle with a screw cap. Fig. $\mathrm{S} 1 \dagger$ presents in detail the steps taken to obtain the 1-D ZnO nanorod-like structures. The hexagonal 1-D ZnO nanorod growth process was carried out with the glass bottle placed in an electric furnace for 4 hours at $110{ }^{\circ} \mathrm{C}$. The film was removed from the solution when the solution attained room temperature, washed with deionized water and alcohol isopropyl, and dried at $80^{\circ} \mathrm{C}$ for 12 hours in an air atmosphere.

\subsection{Characterization techniques}

One-dimensional $\mathrm{ZnO}$ nanostructures were characterized by X-ray diffraction measurements (Diffractometer Rigaku, Ultima IV) with a monochromatic $\mathrm{CuK} \alpha$ radiation source. The data were collected in the $2 \theta=20-80^{\circ}$ range, with a step of $0.02^{\circ}$ and a step scanning at $2^{\circ} \mathrm{min}^{-1}$. The morphological properties of the 1-D ZnO hexagonal nanorods were analyzed in a field emission scanning electron microscope (FE-SEM, Zeiss Supra35) operating at $10 \mathrm{kV}$. The average nanorod size was estimated measuring 150 particles from the FE-SEM images. The microanalysis by energy-dispersive X-ray (EDX) spectroscopy was performed in a spectrometer Thermo Scientific (model $6742 \mathrm{~A})$.

\subsection{Gas sensing measurements}

The sample was inserted into a chamber which allowed control of the substrate temperature and ozone concentrations. Ozone gas was formed from oxidizing oxygen molecules of dry air $\left(8.3 \mathrm{~cm}^{3} \mathrm{~s}^{-1}\right)$ by a calibrated pen-ray UV lamp (UVP, model P/N 90-0004-01), providing ozone concentrations from 0.06 to $1.19 \mathrm{ppm}$. The dry air, containing ozone, was blown directly onto the sample placed on a heated holder. The applied dc voltage was $1 \mathrm{~V}$ and the electrical resistance was measured using a Keithley (model 6514) electrometer. The sensitivity $(S)$ was defined as $S=R_{\text {ozone }} / R_{\text {air }}$, where $R_{\text {ozone }}$ and
$R_{\text {air }}$ are the electric resistance of the sensor exposed to ozone gas and to dry air, respectively.

The sensor response time was defined as the time required for a change in the sample's electrical resistance to reach $90 \%$ of the initial value when exposed to ozone gas. In the same way, the recovery time was defined as the time required for the electrical resistance of the sensor to return $90 \%$ of the initial value after turning off the ozone gas. To determine the long-term stability over period of 190 days, the sample was stored and exposed to $0.1 \mathrm{ppm}$ of ozone at working temperature of $250^{\circ} \mathrm{C}$ every amount of days by measuring the repeated adsorption and desorption cycles (3 cycles were collected).

Gas sensing measurements under UV-light irradiation were performed using a UV-LED (peak wavelength of $351 \mathrm{~nm}$; operating voltage of $3 \mathrm{~V}$ ) at a working temperature of $26^{\circ} \mathrm{C} \pm 1{ }^{\circ} \mathrm{C}$. The distance between the UV-LED and the sensing material was kept at $10 \mathrm{~mm}$. Initially, the sample was irradiated for $30 \mathrm{~min}$ with a UV-LED to stabilize the electrical resistance.

\section{Results and discussion}

Fig. 1a displays the X-ray diffraction (XRD) pattern of 1-D nanostructure ZnO film. All diffraction peaks were indexed as hexagonal wurtzite structures of $\mathrm{ZnO}$ with a $P 6_{3} m c$ space group, according to JCPDS file no. 36-1451. Furthermore, the Zn-K XANES edge spectrum of the 1-D ZnO film revealed that the $\mathrm{Zn}$ is tetrahedrally coordinated by four oxygen atoms, exhibiting an oxidation state of $2+,{ }^{21}$ as shown in Fig. S2 (ESI†े). The EDX spectrum (Fig. S3 $\dagger$ ) confirms $\mathrm{Zn}$, and $\mathrm{O}$ elements in the $\mathrm{ZnO}$ film. The $\mathrm{Si}$ and $\mathrm{C}$ peaks can be attributed to the silicon substrate and residues of HMTA.

Additionally, the (002) XRD peak presented a higher intensity, showing that the sample was preferentially textured along the $c$-axis, in good agreement with the FE-SEM image (Fig. 1b). FE-SEM images also showed that the ZnO film is composed by uniform hexagonal $\mathrm{ZnO}$ nanorod-like structures, as depicted in Fig. $1 \mathrm{c}$ and $\mathrm{d}$. The average diameter and length of the nanorods were $160 \mathrm{~nm}$ and $2 \mu \mathrm{m}$, respectively. The growth process of these $\mathrm{ZnO}$ nanorods via the hydrothermal method has been investigated in many studies ${ }^{22-27}$ and it is well established that it is based on hydrolysis and precipitation reactions..$^{28}$

The electrical resistance of 1-D ZnO nanorods was monitored when exposed to $0.1 \mathrm{ppm}$ of ozone for different periods of time and at a working temperature of $250^{\circ} \mathrm{C}$. As can be seen in Fig. 2, the sample displayed good sensitivity even for shorter exposure times, presented total reversibility and had good stability of the base line. Additionally, the sample did not reach saturation, even for longer exposure times up to 60 seconds, probably due to the high volume/surface ratio of the nanorods.

As is well known, in ozone gas detection, the $\mathrm{O}_{3}$ gas molecules adsorb on the ZnO surface, implying the formation of an electron-depletion layer due to adsorption of ions, which increases the potential barrier and consequently diminishes $\mathrm{ZnO}$ conductivity. ${ }^{29,30}$ The gas response of the 1-D ZnO nanorods can be explained by the following reactions, ${ }^{4}$

$$
\mathrm{O}_{3(\mathrm{~g})}+\mathrm{e}^{-} \rightarrow \mathrm{O}_{2(\mathrm{des})}+\mathrm{O}_{(\mathrm{ads})}{ }^{-}
$$



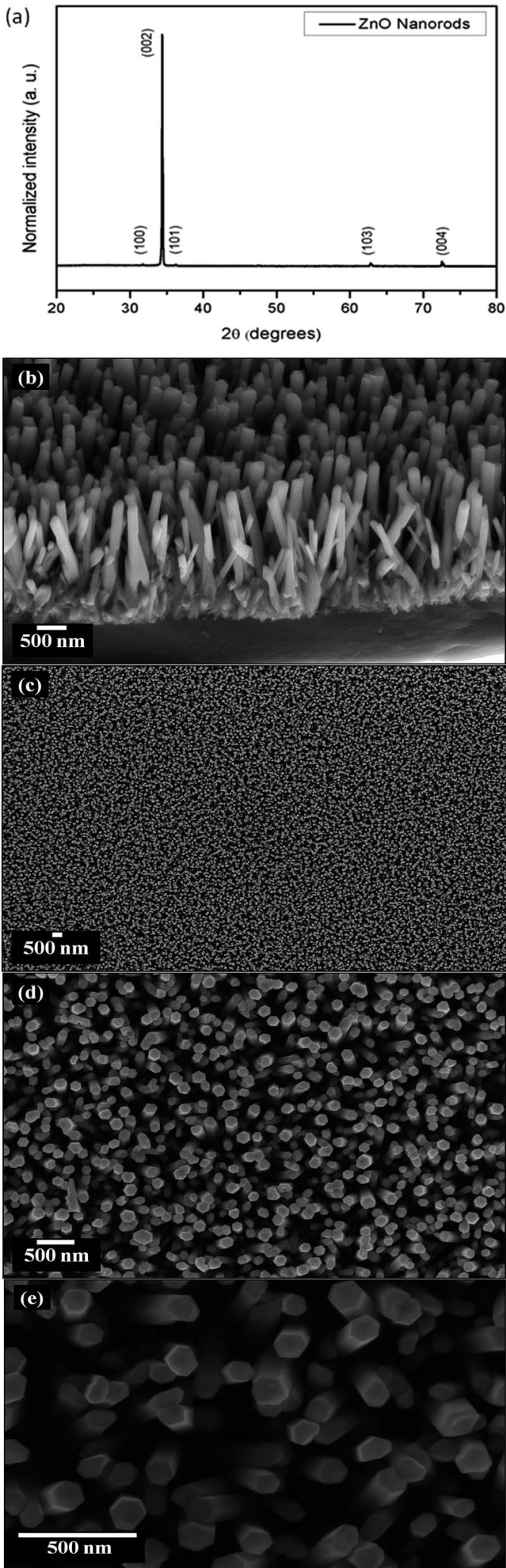

Fig. 1 ZnO nanorods film prepared via hydrothermal method. (a) X-ray diffraction pattern, (b) FE-SEM images of cross-section and (c)-(e) surface microstructure.

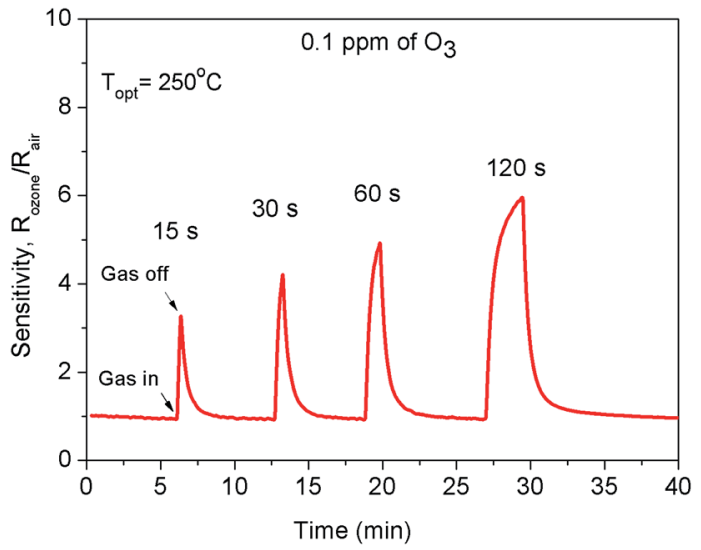

Fig. 2 Ozone gas sensing response of as-prepared $\mathrm{ZnO}$ nanorods exposed to $0.1 \mathrm{ppm}$ for different exposure times $(15 \mathrm{~s}, 30 \mathrm{~s}, 60 \mathrm{~s}$, and $120 \mathrm{~s})$.

In order to determine the optimal working temperature, the sample was exposed for $30 \mathrm{~s}$ to $0.1 \mathrm{ppm}$ of ozone at different temperatures. As can be seen in Fig. 3a, the sensitivity of the 1-D $\mathrm{ZnO}$ nanorods was highest at $250{ }^{\circ} \mathrm{C}$. This temperature has been seen in the literature. ${ }^{31}$ In addition, as displayed in Fig. $3 \mathrm{~b}$, the high surface-to-volume ratio of the nanorod-like structures favored the adsorption/desorption processes, presenting a fast
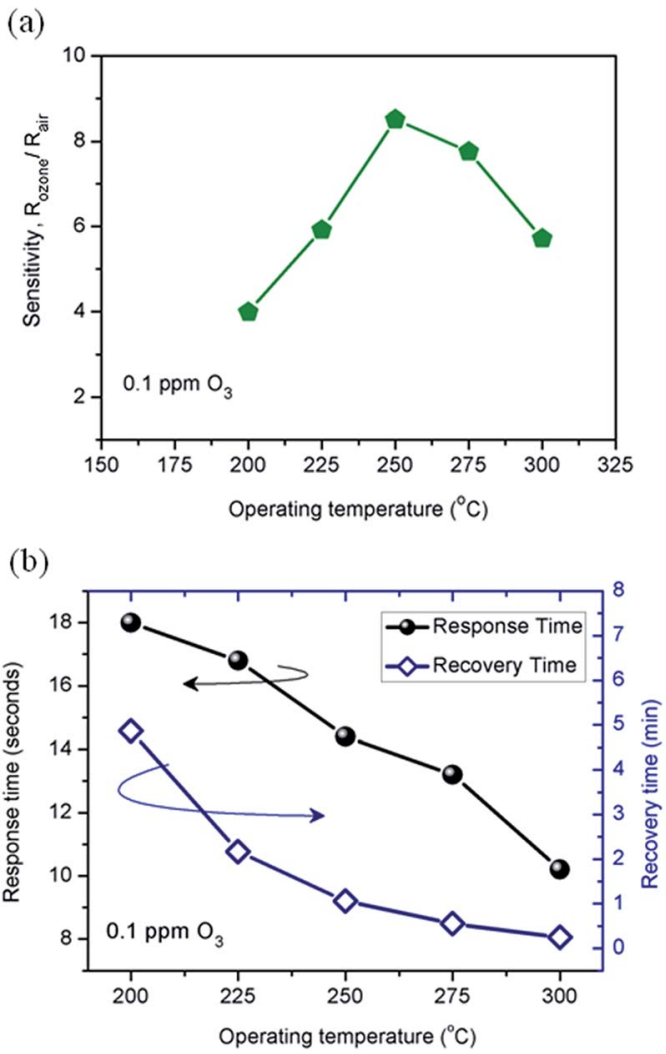

Fig. 3 Ozone gas sensing properties of $\mathrm{ZnO}$ nanorods film. (a) Sensitivity and (b) response and recovery time towards $0.1 \mathrm{ppm} \mathrm{O}_{3}$ at various operating temperatures. 
response time (10-18 s) and a recovery time varying from $15 \mathrm{~s}$ to 5 min.

The gas sensing response was then studied with different ozone concentrations and at a working temperature of $250{ }^{\circ} \mathrm{C}$, as displayed in Fig. 4. For each measurement cycle, the sample was exposed for $30 \mathrm{~s}$. Fig. 4a shows reversible cycles of the response curve indicating a stable and reproducible response. It can be seen that the resistances of the samples are increased upon to exposure to oxidizing gas, indicating the n-type semiconductor behavior. It is important to note that after several exposure cycles the 1-D ZnO sample detected lower ozone concentration, demonstrating good reversibility. Furthermore, the sensitivity of the 1-D ZnO nanorods increased with ozone concentration and reached saturation at $1.19 \mathrm{ppm}$, as shown in Fig. 4.

Fig. 5 shows the $\mathrm{ZnO}$ nanorods' sensitivity to $0.1 \mathrm{ppm}$ of $\mathrm{O}_{3}$ at working temperature of $250{ }^{\circ} \mathrm{C}$, over a 190 day period. A slight variation of the gas sensor response, demonstrating long-term stability of the sample, is the average sensitivity value of 5.2 with a standard deviation of 0.5 .

Although the results presented here confirm that 1-D ZnO nanorods present a significant sensitivity to ozone around $250{ }^{\circ} \mathrm{C}$, an effort has been made to decrease the operating temperature, and other studies have focused on developing gas sensors that work at room temperature.
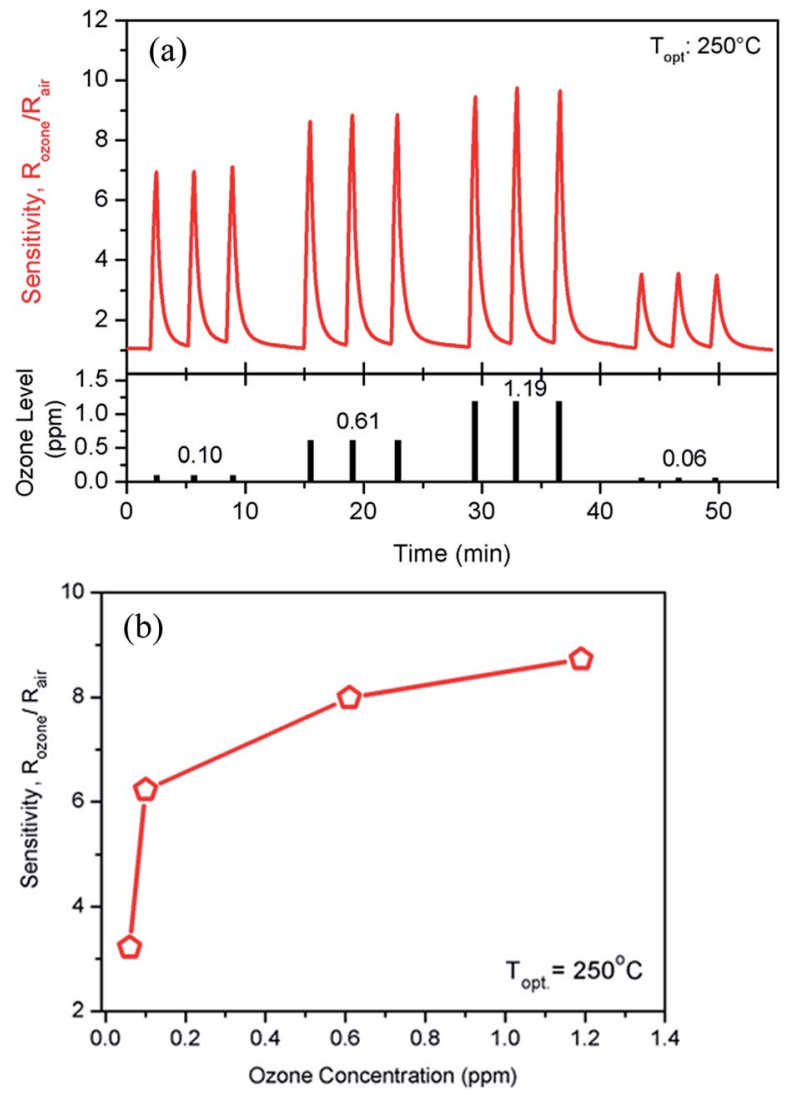

Fig. $4 \mathrm{ZnO}$ nanorods at an operating temperature of $250{ }^{\circ} \mathrm{C}$ (a) sensitivity and (b) sensitivity vs. Ozone concentration.

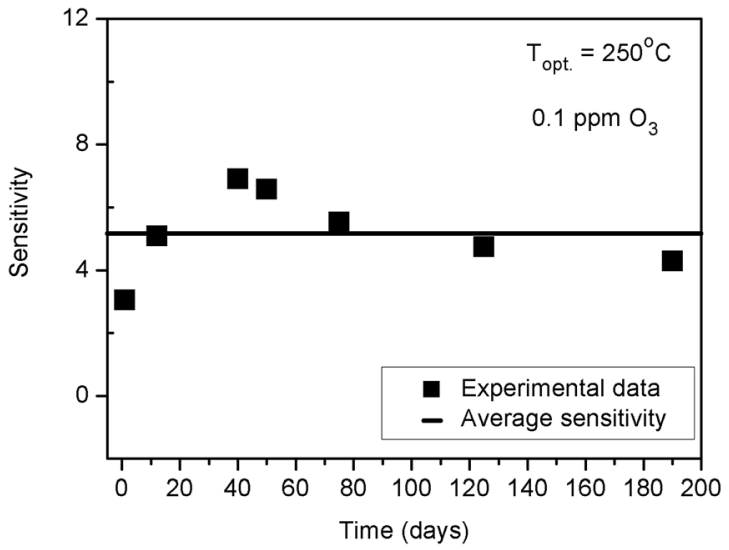

Fig. 5 Stability of the $\mathrm{ZnO}$ film during 190 days to $0.1 \mathrm{ppm}$ of ozone.

The sample studied here was initially exposed to ozone at room temperature (around $26^{\circ} \mathrm{C}$ ) without any illumination, and as can be seen in Fig. 6a, a slight ozone response was observed with a longer recovery time. On the other hand, when the sample was exposed to ozone under UV illumination, Fig. 6b, the sensitivity to ozone gas was enhanced over that without UV light. As showed in Fig. 6b, the 1-D ZnO nanorods exhibited a

(a)

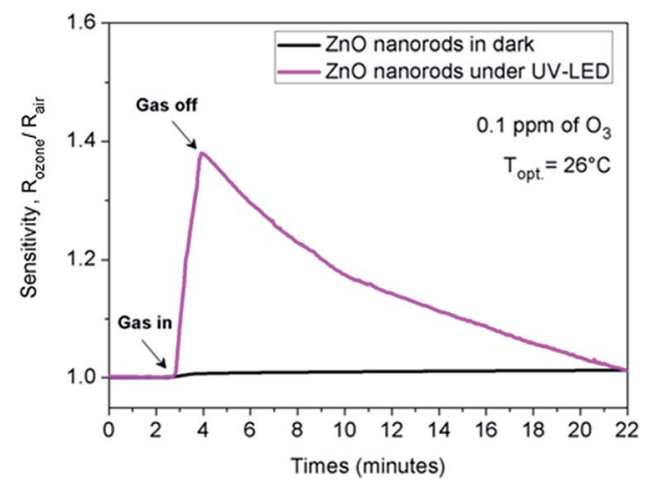

(b)

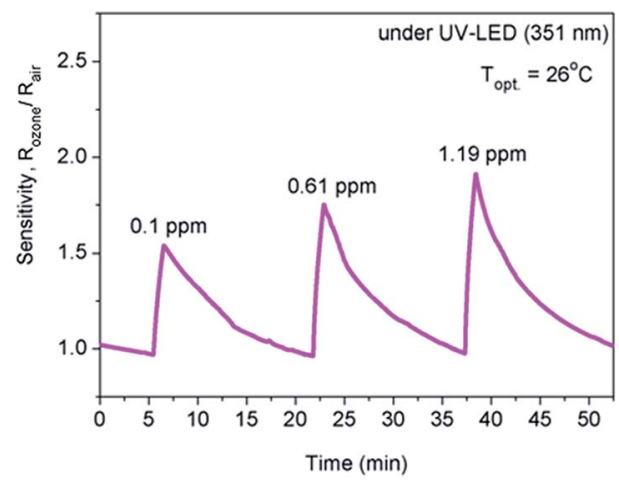

Fig. 6 Ozone sensitivity of $\mathrm{ZnO}$ nanorods at room temperature (a) in dark (black curve) and under UV-light exposition (magenta curve) towards $0.1 \mathrm{ppm}$ of $\mathrm{O}_{3}$ and (b) at various ozone levels operating under UV-light irradiation. 
good gas sensing response towards different ozone levels when kept under UV irradiation. The sample exhibited a response time between 40 and $44 \mathrm{~s}$, and a recovery time varying between 9 and $11 \mathrm{~min}$, depending on $\mathrm{O}_{3}$ level.

The ozone sensing mechanism of $\mathrm{ZnO}$ nanorod-like structures under UV light can be explained as follow:

First, when the 1-D ZnO nanorods are exposed to an air atmosphere, oxygen molecules are adsorbed on the different ZnO surfaces,

$$
\mathrm{O}_{2 \text { (gas) }} \rightarrow \mathrm{O}_{2(\mathrm{ads})}
$$

These oxygen molecules capture free electrons from the $\mathrm{ZnO}$ conduction band, forming ionized oxygen anions. ${ }^{32}$ At temperatures $<150{ }^{\circ} \mathrm{C}$, the ionic species $\mathrm{O}_{2}{ }^{-}$are dominant, ${ }^{30}$

$$
\mathrm{O}_{2(\mathrm{ads})}+\mathrm{e}^{-} \rightarrow \mathrm{O}_{2(\mathrm{ads})}{ }^{-}
$$

These $\mathrm{O}_{2}^{-}$species contribute to form a high-resistance depletion layer in the nanorod surfaces, increasing electrical resistance in the nanorods (Fig. $\mathrm{S} 4 \dagger$ ). When the nanorods are exposed to UV irradiation $(3.53 \mathrm{eV})$, electron-hole pairs are photogenerated $\left(h v \rightarrow \mathrm{h}^{+}+\mathrm{e}^{-}\right.$) in the $\mathrm{ZnO}$ surface, because the photon energy is larger than the $\mathrm{ZnO}$ band gap. ${ }^{31,33,34}$ The photogenerated holes $\left(\mathrm{h}^{+}\right)$migrate to the $\mathrm{ZnO}$ surface, and $\mathrm{O}_{2}{ }^{-}$species are photodesorbed,

$$
\mathrm{h}^{+}(h v)+\mathrm{O}_{2(\mathrm{ads})}{ }^{-} \rightarrow \mathrm{O}_{2(\mathrm{~g})}(h v)
$$

As consequence, the depletion layer is diminished and the remaining unpaired electrons contribute to an increase in the electrical conductivity, as shown in Fig. S4. $\dagger$ Upon exposure to $\mathrm{O}_{3}$ gas, $\mathrm{O}_{3}$ molecules adsorb on the $\mathrm{ZnO}$ surfaces, as shown in the following reaction:

$$
\mathrm{O}_{3(\mathrm{~g})}+\mathrm{e}^{-}(h v) \rightarrow \mathrm{O}_{2(\mathrm{des})}(h v)+\mathrm{O}_{2(\mathrm{ads})}{ }^{-}(h v) .
$$

This reaction widens the depletion-layer in the $\mathrm{ZnO}$ surface, hindering the flux of charge carriers, and consequently, the electrical resistance is increased when the sensing material is exposed to $\mathrm{O}_{3}$ gas, as shown in Fig. 6 .

\section{Conclusions}

This work reported a low-temperature way to prepare an ozone gas sensor based on hexagonal 1-D ZnO nanorod-like structures grown via a hydrothermal process. Gas sensing measurements showed the great potential of these $\mathrm{ZnO}$ nanorods, which display a fast response (of $c a .14 \mathrm{~s}$ ), short recovery time (of $c a .60$ s), and long-term stability for a period of over 6 months at optimal temperature of $250{ }^{\circ} \mathrm{C}$. In addition to excellent ozone detection at $250^{\circ} \mathrm{C}$, the sample also showed a good sensitivity to ozone at room temperature under UV-light irradiation. This versatile methodology may provide an alternative way to manufacture gas sensor devices, growing them at low temperatures on flexible substrates which operate at room temperature.

\section{Acknowledgements}

The authors acknowledge the financial support of the Brazilian research funding institution CNPq and FAPESP (2013/07296-2; 2013/09573-3; 2012/15170-6). This research was partially performed at the Brazilian Laboratory Synchrotron Radiation (LNLS- 9474) and LNNano-Microfabrication laboratory (Project 17168), Campinas, SP, Brazil.

\section{Notes and references}

1 T. Xiao, X. Y. Wang, Z. H. Zhao, L. Li, L. Zhang, H. C. Yao, J. S. Wang and Z. J. Li, Sens. Actuators, B, 2014, 199, 210-219.

2 Y. L. Tang, Z. J. Li, J. Y. Ma, Y. J. Guo, Y. Q. Fu and X. T. Zu, Sens. Actuators, B, 2014, 201, 114-121.

3 L. Gu, K. Zheng, Y. Zhou, J. Li, X. Mo, G. R. Patzke and G. Chen, Sens. Actuators, B, 2011, 159, 1-7.

4 G. Korotcenkov and B. K. Cho, Sens. Actuators, B, 2012, 161, 28-44.

5 G. J. Cadena, J. Riu and F. X. Rius, Analyst, 2007, 132, 10831099.

6 S. Yi, S. Tian, D. Zeng, K. Xu, S. Zhang and C. Xie, Sens. Actuators, B, 2013, 185, 345-353.

7 L. F. da Silva, A. C. Catto, W. Avansi Jr, L. S. Cavalcante, J. Andrés, K. Aguir, V. R. Mastelaro and E. Longo, Nanoscale, 2014, 6, 4058-4062.

8 R. S. Devan, R. A. Patil, J. H. Lin and Y. R. Ma, Adv. Funct. Mater., 2012, 22, 3326-3370.

9 J. Huang and Q. Wan, Sensors, 2009, 9, 9903-9924.

10 S. Barth, F. H. Ramirez, J. D. Holmes and A. R. Rodriguez, Prog. Mater. Sci., 2010, 55, 563-627.

11 D. Bekermann, A. Gasparotto, D. Barreca, A. Devi, R. A. Fischer, M. Kete, U. Štangar, O. I. Lebedev, C. Maccato, E. Tondello and G. V. Tendeloo, ChemPhysChem, 2010, 11, 2337-2340.

12 F. S. S. Chien, C. R. Wang, Y. L. Chan, H. L. Lin, M. H. Chen and R. J. Wu, Sens. Actuators, B, 2010, 144, 120-125.

13 B. S. Kang, Y. W. Heo, L. C. Tien, D. P. Norton, F. Ren, B. P. Gila and S. J. Pearton, Appl. Phys. A, 2005, 80, 10291032.

14 S. Pati, P. Banerji and S. B. Majumder, Sens. Actuators, A, 2014, 213, 52-58.

15 N. H. Como, S. Moreno, I. Mejia and M. A. Q. Lopez, Semicond. Sci. Technol., 2014, 29, 085008.

16 C. Y. Lu, S. P. Chang, S. J. Chang, T. J. Hsueh, C. L. Hsu and Y. Z. Chiou, IEEE Sens. J., 2009, 9, 485-489.

17 S. L. Bai, C. Sun, T. Guo, R. Luo, Y. Lin, A. Chen, L. Sun and J. Zhang, Electrochim. Acta, 2013, 90, 530-534.

18 G. Kenanakis, D. Vernardou, E. Koudoumas, G. Kiriakidis and N. Katsarakis, Sens. Actuators, B, 2007, 124, 187-191.

19 N. Kilinc, O. Cakmak, A. Kosemen, E. Emek, S. Ozturk, Y. Yerli, Z. Z. Ozturk and H. Urey, Sens. Actuators, B, 2014, 202, 357-364.

20 M. R. Alenezi, S. J. Henley, N. G. Emerson and S. R. P. Silva, Nanoscale, 2014, 6, 235-247.

21 H. Liu, F. Zeng, S. Gao, G. Wang, C. Song and F. Pan, Phys. Chem. Chem. Phys., 2013, 15, 13153-13161. 
22 T. L. Sounart, J. Liu, J. A. Voigt, J. W. P. Hsu, E. D. Spoerke, Z. Tian and Y. B. Jiang, Adv. Funct. Mater., 2006, 16, 335-344. 23 J. Song and S. Lim, J. Phys. Chem. C, 2007, 111, 596-600.

24 K. Govender, D. S. Boyle, P. B. Kenway and P. O'Brien, J. Mater. Chem., 2004, 14, 2575-2591.

25 R. Savu, R. Parra, E. Joanni, B. Jancar, S. A. Elizário, R. de Camargo, P. R. Bueno, J. A. Varela, E. Longo and M. A. Zaguete, J. Cryst. Growth, 2009, 311, 4102-4108.

26 S. V. Costa, A. G. Gonçalves, M. A. Zaguete, T. Mazon and A. F. Nogueira, Chem. Commun., 2013, 49, 8096-8098.

27 Y. V. Kaneti, Z. Zhang, J. Yue, Q. M. D. Zakaria, C. Chen, X. Jiang and A. Yu, Phys. Chem. Chem. Phys., 2014, 16, 11471-11480.
28 X. D. Yan, Z. Li, R. Chen and W. Gao, Cryst. Growth Des., 2008, 8, 2406-2410.

29 D. Barreca, D. Bekermann, E. Comini, A. Devi, R. A. Fischer, A. Gasparotto, C. Maccato, C. Sada, G. Sberveglieri and E. Tondello, CrystEngComm, 2010, 12, 3419-3421.

30 H. J. Kim and J. H. Lee, Sens. Actuators, B, 2014, 192, 607-627. 31 M. Bendahan, J. Guerin, R. Boulmani and K. Aguir, Sens. Actuators, B, 2007, 124, 24-29.

32 J. Gong, Y. Li, X. Chai, Z. Hu and Y. Deng, J. Phys. Chem. C, 2010, 114, 1293-1298.

33 S. Park, S. An, Y. Mun and C. Lee, ACS Appl. Mater. Interfaces, 2013, 5, 4285-4292.

34 Y. Mun, S. Park, S. An, C. Lee and H. W. Kim, Ceram. Interfaces, 2013, 39, 8615-8622. 